\title{
Vulnerability and quality of life of older persons in the community in different situations of family care
}

\author{
Vulnerabilidade e qualidade de vida de pessoas idosas em diferentes situações de atenção familiar
}

Vulnerabilidad y calidad de vida de los mayores em la comunidade em diferentes situaciones de cuidado familiar

'Universidade Federal de São Paulo. São Paulo, São Paulo, Brazil.

How to cite this article:

Perseguino MG, Okuno MFP, Horta ALM. Vulnerability and quality of life of older persons in the community in different

situations of family care. Rev Bras Enferm. 2022;75(Suppl 4):e20210034. https://doi.org/10.1590/0034-7167-2021-0034

Corresponding author:

Marcelo Geovane Perseguino

E-mail:marcelogp@yahoo.com

EDITOR IN CHIEF: Antonio José de Almeida Filho ASSOCIATE EDITOR: Ana Fátima Fernandes
Approval: 05-10-2021

\begin{abstract}
Objective: to correlate socio-contextual aspects, physical vulnerability and quality of life of older persons in the community in different situations of family care. Methods: epidemiological, a cross-sectional and analytical study, with elderly people in the community $(n=769)$, with application of the instruments: Vulnerable Elders Survey-13 (VES-13), World Health Organization Quality of Life for Older Persons (WHOQOL-OLD) and the World Health Organization Quality of Life (WHOQOL-BREF); and socio-contextual data questionnaire. Results: the population assessed presented an average of regular quality of life in both the WHOQOL-BREF and the WHOQOL-OLD. Older non-vulnerable persons (62.2\%) and those with close family contact $(82.6 \%)$ have a better quality of life than the vulnerable $(p<0.0001)$. Conclusion: lower quality of life scores and more distant families are related to vulnerable elderly people; thus, the assessment of family proximity and physical vulnerability of older persons is shown to be an important factor in improving quality of life.

Descriptors: Aged; Geriatric Nursing; Quality of Life; Family; Health Vulnerability.
\end{abstract}

\section{RESUMO}

Objetivo: correlacionar aspectos sociocontextuais, vulnerabilidade física e a qualidade de vida de pessoas idosas na comunidade em diferentes situações de atenção familiar. Métodos: estudo epidemiológico, transversal e analítico, com pessoas idosas na comunidade $(\mathrm{n}=769)$, com aplicação dos instrumentos: Vulnerable Elders Survey-13 (VES-13), World Health Organization Quality of Life for Older Persons (WHOQOL-OLD) e o World Health Organization Quality of Life (WHOQOL-BREF); e questionário de dados sóciocontextual. Resultados: a população avaliada apresentou média de regular qualidade de vida tanto no WHOQOL-BREF quanto no WHOQOL-OLD. Pessoas idosas não vulneráveis $(62,2 \%)$ e com contato familiar próximo $(82,6 \%)$ apresentam melhor qualidade de vida do que os vulneráveis $(p<0,0001)$. Conclusão: menores escores de qualidade de vida e famílias mais distantes estão relacionados a pessoas idosas vulneráveis; assim, a avaliação da proximidade familiar e vulnerabilidade física da pessoa idosa se mostra como um fator importante de melhora na qualidade de vida. Descritores: Idoso; Enfermagem Geriátrica; Qualidade de Vida; Família; Vulnerabilidade em Saúde.

\section{RESUMEN}

Objetivo: correlacionar aspectos socio-contextuales, vulnerabilidad física y calidad de vida de las personas mayores de la comunidad en diferentes situaciones de cuidado familiar. Métodos: estudio epidemiológico, transversal y analítico, con personas mayores de la comunidad ( $n=769$ ), con aplicación de los instrumentos:Vulnerable Elders Survey-13 (VES-13), World Health Organization Quality of Life for Older Persons (WHOQOL-OLD) y World Health Organization Quality of Life (WHOQOL-BREF); y cuestionario de datos socio-contextuales. Resultados: la población evaluada presentó un promedio de calidad de vida regular tanto en WHOQOL-BREF como en WHOQOL-OLD. Los ancianos no vulnerables $(62,2 \%)$ y aquellos con contacto familiar cercano $(82,6 \%)$ tienen una mejor calidad de vida que los vulnerables $(p<0,0001)$. Conclusión: los puntajes de calidad de vida más bajos y las familias más distantes se relacionan con las personas mayores vulnerables; así, la evaluación de la proximidad familiar y la vulnerabilidad física del anciano se muestra como un factor importante en la mejora de la calidad de vida.

Descriptores: Anciano; Enfermería Geriátrica; Calidad de Vida; Familia;Vulnerabilidad en Salud. 


\section{INTRODUCTION}

The aging process and economic development are a reality progressively experienced by developed countries in Europe and North America, accentuated after World War II. Currently, this reality also extends to developing countries, but with no impact on economic improvement and the population's quality of life, as is the case in Brazil, where the accelerated process of population aging occurs parallel to slow economic development and improvement of the population's quality of life ${ }^{(1-2)}$.

Population aging is accompanied by longevity and, with it, the need for care. Thus, governments and society will need to review problem-solving strategies for the aging population worldwide, especially those related to primary care such as health promotion, prevention of chronic non-communicable and communicable diseases. Rapid and significant changes in health systems and social care services are needed to ensure an improvement in the quality of life of this population and their well-being and care ${ }^{(3-5)}$.

With longevity, dependency and physical vulnerability become increasingly present in the lives of older persons and their families. The concept of physical vulnerability refers to being at risk, as older persons are linked to the physiological functional limitations of aging, related to the progressive loss of capacity and control of basic functional capacities, such as mood, cognition, mobility, and communication. Socio-contextual factors, such as family income, family and psychological support, access to knowledge and education, social inclusion and family support, are factors that strongly influence the classification of physical vulnerability and quality of life ${ }^{(6-8)}$.

Maintaining the quality of life of this new population profile is essential to ensure a healthy and socially participatory population. Essential aspects, such as maintaining independence and autonomy, good family functionality, preservation of the social role and productive activity, positive self-perception of health, maintenance of relationships, access, emotional comfort, spirituality, housing and financial security, must be guaranteed and associated to that older persons can maintain their quality of life. The concept of older persons' quality of life must be seen as a dynamic network of intertwined needs ${ }^{(9-13)}$.

Thus, the question arises about the relationship between physical vulnerability and the quality of life of older persons in different situations of family proximity and what care strategies can be taken for better health care for this population, as the gap identified in literature production, relating the influence of family proximity on older persons' vulnerability and quality of life. This research can support the interprofessional nursing and health teams in the development of more effective care plans to maintain quality of life and reduce physical vulnerability.

\section{OBJECTIVE}

To correlate socio-contextual aspects, physical vulnerability and quality of life of older persons in the community in different situations of family care.

\section{METHODS}

\section{Ethical aspects}

The research was developed in compliance with national and international standards of ethics in research with human beings, in accordance with Resolution 466/12, after authorization from the Institutional Review Board of the responsible institution.

\section{Study design, period, and place}

This is an epidemiological, cross-sectional and analytical study, carried out in the Integrated Health Outpatient Clinics of a private university in the city of São Paulo, from June 2017 to March 2018.

Data collection took place in three interprofessional school outpatient clinics, providing free service to the population in the fields of nursing, pharmacy, physiotherapy, medicine, nutrition, dentistry, psychology and social service, comprising three units in different regions of the city of São Paulo (Vila Maria, Vergueiro, and Barra Funda), assisting an annual mean of 15,000 patients, among them 8,000 older persons, in care for health promotion and prevention, primary and secondary care and rehabilitation.

\section{Population or sample, inclusion and exclusion criteria}

People over 65 years of age, who lived with their relatives, or in a single-person household, or with their spouse and older persons, residing in the city of São Paulo, registered in the university Integrated Health Outpatient Clinic, were listed. Older persons over 65 years of age were included because, according to the World Health Organization (WHO), this group has characteristics that increase the risk of physical vulnerability and frailty, although in Brazil those over 60 years of age are considered elderly. Those who had a medical diagnosis of cognitive disorders or a result of an assessment by the Geriatric Depression Scale were excluded from the study, showing a risk of depression and a medical diagnosis that could prevent the completion of the data collection instruments.

All older persons assisted by the place of study are evaluated, in an initial consultation, through Mini Mental State Examination (MMSE) instruments. MMSE consists of 30 questions scored with 1 point each, for a total of 30 points, however, depending on the level of education of the person evaluated ( 29 for people with at least nine years of education, 26 for those with five to eight years of education and 22 for those with zero to four years of education); lower values may indicate cognitive impairment, and by the GDS Geriatric Depression Scale instrument, consisting of 15 questions, with objective answers, with a value of one point each with depressive signs, with total values greater than 6 points indicative of signs of depression.

\section{Study protocol}

The calculation of the sample size was performed using the stratified probability sampling method proportional to the average number of older persons over 65 years of age served in the year preceding the survey, taking into account the approximate total 
of 8,000 patients seen at the school's outpatient clinics, considering a confidence level of $\geq 95 \%$ and alpha of $5 \%$, based on the inclusion and exclusion factors of the study analyzed in medical records. After analyzing the medical records of older persons assisted at an Integrated Health Outpatient Clinic, carried out by the researcher, 1,234 older persons who met the eligibility criteria were listed. Subsequently, they were contacted by telephone, and an interview was scheduled for the 769 people who accepted the invitation to participate in data collection. The interviews lasted a mean of 45 minutes.

Among the 465 older persons who did not accept to participate in the study, 236 reported having difficulty attending the service due to partial or total physical limitations that impeded locomotion and transportation to the interview site; the other 229 older persons reported having no interest in participating.

Three data collection instruments were applied by the authors themselves, known as Vulnerable Elders Survey-13 (VES-13), World Health Organization Quality of Life for Older Persons (WHOQOL-OLD) and World Health Organization Quality of Life (WHOQOL-BREF). A structured questionnaire was also applied to collect socio-contextual data: gender, age, marital status, education, family income, type of residence and number of people with whom they cohabit and work ${ }^{(14-15)}$. A pilot test was not carried out, since the instruments used in the data collection process are widely used in research work in the national territory and other countries and present significant results in the literature.

The VES-13 is a simple and reliable instrument for the identification and tracking of vulnerable older persons aged 65 years and over who are at risk of functional decline or death within two years, valuing factors such as age, self-perception of health, the presence of physical limitations and disabilities ${ }^{(16)}$ and a formal assessment of the general and referential meanings was performed in order to obtain a synthesis version. Understanding of the synthesis version was evaluated in a pretest applied to 33 patients in an oncologic hospital of the Brazilian Unified National Health System (SUS. It is an assessment scale consisting of ten points, with each question having its specific score, thus enabling the assessment of functional decline if the score is greater than 3 points, unrelated to gender and multi-comorbidities ${ }^{(15-16)}$ and a formal assessment of the general and referential meanings was performed in order to obtain a synthesis version. Understanding of the synthesis version was evaluated in a pretest applied to 33 patients in an oncologic hospital of the Brazilian Unified National Health System (SUS.

TheWHOQOL-BREF quality of life assessment instrument consists of the simplified version of the WHOQOL-100 instrument, used worldwide to assess adults' quality of life, being instruments validated in Brazil that have good reliability for our population. WHOQOLOLD consists of a complementary module to WHOQOL-BREF, with 24 questions related to sensory abilities, autonomy, social participation, death, and intimacy, being very effective in assessing older persons' quality of life, including aspects relevant to older persons not covered in WHOQOL-BREF. The instruments have a maximum score of five points, with five equal to very good quality of life and one to poor ${ }^{(14)}$.

\section{Analysis of results, and statistics}

Data were stored in an MS-Excel ${ }^{\circ}$ spreadsheet. Statistical analyzes involving hypothesis testing were processed in the software Statistical Package for Social Sciences, version 22.0.

For descriptive analysis of continuous variables, the mean, standard deviation, median, minimum and maximum were calculated. For categorical variables, frequency and percentage were calculated. To assess the influence of socio-contextual aspects on physical vulnerability, the chi-square test was used. When necessary, the Likelihood Ratio Test was used.

To assess the influence of socio-contextual aspects on the quality of life score, the non-parametric Mann-Whitney test (2 categories) or Kruskal-Wallis (3 or more categories) was used. To assess the influence of age and number of children on physical vulnerability, the nonparametric Mann-Whitney test (2 categories) or the Kruskal-Wallis test (3 or more categories) were used.

To assess the influence of age and number of children on the quality of life score, Spearman's correlation coefficient was used. To compare the quality of life of older persons with vulnerability, in different care situations and family dynamics, the General Linear Model was used. A significance level of $5 \%$ was used ( $p$ value $<0.05$ )

\section{RESULTS}

From the sample of 769 evaluated, the mean age was 71.91 years. Most were women (61.4\%), married $(50.3 \%)$, with a mean of 3.3 children, retired $(51.7 \%)$, lived with up to three people (36.3\%), with incomplete primary education (46.6\%), considered their family income sufficient (57.9\%), had close family contact (86.2\%), did not receive family support (49\%), had their own residence (86\%) and does not currently work (72.7\%).

Regarding vulnerability, $62.2 \%$ of older persons were not vulnerable, but $37.8 \%$ were assessed as vulnerable. When compared with the gender variable, the results show that older female persons have a higher percentage of vulnerability when compared to males $(p=0.001)$.

Widowed people have a higher percentage of vulnerability than older persons from other civil states $(p=0.0000)$. Older persons who work also have a lower percentage of vulnerability when compared to retirees and those who do not work $(p=0.0000)$. Older persons with incomplete higher education have a higher percentage of non-vulnerability than those with less education $(p<0.0001)$.
Table 1 - World Health Organization Quality of Life-BREF and World Health Organization Quality of Life domain scores for Older Persons of older persons in the community $(n=769)$, São Paulo, São Paulo, Brasil, 2017-2018

\begin{tabular}{|c|c|c|c|}
\hline $\begin{array}{l}\text { WHOQOL-BREF } \\
\text { domains }\end{array}$ & Mean (SD*) & $\begin{array}{l}\text { WHOQOL-OLD } \\
\text { domains }\end{array}$ & Mean $\left(S D^{*}\right)^{* *}$ \\
\hline Physical & $3.64(0.65)$ & Sensory ability & $3.89(0.91)$ \\
\hline Psychological & $3.84(0.63)$ & Autonomy & $3.52(0.81)$ \\
\hline Social relationships & $3.68(0.71)$ & Past, present, and future activities & $3.66(0.71)$ \\
\hline \multirow{3}{*}{ Environment } & $3.4(0.61)$ & Social participation & $3.52(0.72)$ \\
\hline & & Death and dying & $3.67(1.11)$ \\
\hline & & Intimacy & $3.62(0.97)$ \\
\hline
\end{tabular}


Table 2 - Correlation between World Health Organization Quality of Life for Older Persons and World Health Organization Quality of Life-BREF domains with the physical vulnerability of older persons in the community (N=769), São Paulo, São Paulo, Brazil, 2017-2018

\begin{tabular}{lccc}
\hline & \multicolumn{2}{c}{ VES-13 } & \\
& $\begin{array}{c}\text { Not vulnerable } \\
\text { Mean (SD*)** }\end{array}$ & $\begin{array}{c}\text { Vulnerable } \\
\text { Mean (SD*)** }\end{array}$ & p value \\
\hline WHOQOL-OLD & & & \\
$\quad$ Sensory ability & $4.13(0.76)$ & $3.5(1)$ & $<\mathbf{0 . 0 0 0 1}$ \\
Autonomy & $3.74(0.74)$ & $3.14(0.79)$ & $<\mathbf{0 . 0 0 0 1}$ \\
Past, present, and future activities & $3.78(0.65)$ & $3.45(0.75)$ & 0.0001 \\
Social participation & $3.66(0.68)$ & $3.29(0.72)$ & $<\mathbf{0 . 0 0 0 1}$ \\
Death and dying & $3.78(1.07)$ & $3.48(1.14)$ & 0.0243 \\
Intimacy & $3.76(0.92)$ & $3.39(1.01)$ & 0.0010 \\
WHOQOL-BREF & & & \\
Physical & $3.87(0.54)$ & $3.26(0.64)$ & $<\mathbf{0 . 0 0 0 1}$ \\
Psychological & $3.99(0.55)$ & $3.59(0.66)$ & $<\mathbf{0 . 0 0 0 1}$ \\
Social relationships & $3.79(0.7)$ & $3.49(0.68)$ & 0.0001 \\
Environment & $3.48(0.59)$ & $3.25(0.63)$ & 0.0015 \\
Number of appraised & 469 & 300 & 769
\end{tabular}

${ }^{*}$ SD $=$ Standard deviation. General Linear Model; **Cut-off grades: 1 to 2.9 (needs improvement), 3 to 3.9 (fair), 4 to 4.9 (good), 5 (very good).

Table 3 - Correlation between World Health Organization Quality of Life for Older Persons domains and physical vulnerability with family contact of older persons in the community (N=769), São Paulo, São Paulo, Brazil, 2017-2018

\begin{tabular}{lccc}
\hline & \multicolumn{2}{c}{ VES-13 } & \multirow{2}{*}{ Total } \\
& Not vulnerable & Vulnerable & \\
\hline WHOQOL-OLD - Close & & & \\
Mean \pm SD & $3.85(0.53)$ & $3.43(0.57)$ & $3.69(0.58)$ \\
Median & 3.9 & 3.4 & 3.8 \\
Minimum-maximum & $1.9-5$ & $2-4.9$ & $1.9-5$ \\
WHOQOL-OLD - Away/no contact & & & \\
Mean \pm SD & $3.55(0.54)$ & $3.04(0.59)$ & $3.35(0.61)$ \\
Median & 3.5 & 3.0 & 3.3 \\
Minimum-maximum & $2.2-4.7$ & $2.1-4.1$ & $2.1-4.7$ \\
Number of appraised & 469 & 300 & 769 \\
$\quad p$ value (Family Contact) & $<\mathbf{0 . 0 0 0 1}$ & & \\
$p$ value (VES-13) & $<\mathbf{0 . 0 0 0 1}$ & & \\
$p$ value (Family contact x VES-13) & 0.8420 & & \\
\hline General Linear Model; ** Cut-off grades: 1 to 2.9 (needs improvement), 3 to 3.9 (fair), 4 to 4.9 (good), 5 (very good).
\end{tabular}

Table 4 - Correlation between World Health Organization Quality of Life-BREF domains and physical vulnerability with the family contact of older persons in the community ( $N=769)$, São Paulo, São Paulo, Brazil, 2017-2018

\begin{tabular}{lccc}
\hline \multirow{2}{*}{ WHOQOL- BREF/Family contact } & \multicolumn{2}{c}{ VES-13 } & \multirow{2}{*}{ Total } \\
& Not vulnerable & Vulnerable & \\
\hline W-BREF - Close & & & \\
Mean \pm SD & $3.84(0.47)$ & $3.46(0.54)$ & $3.7(0.53)$ \\
Median & 3.9 & 3.5 & 3.8 \\
Minimum-maximum & $2-4.9$ & $1.8-4.8$ & $1.8-4.9$ \\
W-BREF - Away/no contact & & & \\
$\quad$ Mean SD & $3.39(0.54)$ & $3(0.52)$ & $3.24(0.56)$ \\
Median & 3.4 & 3.0 & 3.2 \\
Minimum-maximum & $2.1-4.5$ & $1.8-4$ & $1.8-4.5$ \\
Number of appraised & 469 & 300 & 769 \\
$p$ value (Family Contact) & $<\mathbf{0 . 0 0 0 1}$ & & \\
$p$ value (VES-13) & $<\mathbf{0 . 0 0 0 1}$ & & \\
$p$ value (Family contact x VES-13) & 0.5231 & & \\
\hline Modelo Linear Geral; ** Notas de corte: 1 a 2,9 (necessita melhorar), 3 a 3,9 (regular), 4a 4,9(boa), 5 (muito boa).
\end{tabular}

$(p=0.0000)$ and to the physical domain $(p=0.0001)$. Married people have a higher WHOQOL-OLD score than single and widowed people $(p=0.0000)$, with a higher score in the intimacy domain $(p=0.0000)$ and a higher WHOQOL-BREF score than widowers $(p=0.0015)$, with the highest score related to the physical domain $(p=0.0007)$. Those who still work have a higher sensory functioning score $(p=0.0338)$ and autonomy $(p=0.0369)$ than those who do not work.

Sufficient family income and owning a home provided a higher total score of the WHOQOL-OLD and the WHOQOL-BREF ( $p=0.0000)$, with higher scores in the present-past and future, social, psychological and environmental participation domains $(p=0.0000)$. Those with close family contact had better total scores in both WHOQOL-OLD and WHOQOL-BREF $(p=0.0000)$, except in the death and dying domain $(p=0.0594)$. Older persons with higher education had better total scores in both the WHOQOL-OLD and the WHOQOL-BREF ( $p<0.0001)$. Illiterate people had lower WHOQOL-OLD and WHOQOL-BREF total scores, with the exception of the death and dying domain $(p=0.0148)$ and the social domain $(p=0.001)$.

There is a significant negative correlation between age and the total score ofWHOQOL-OLD and WHOQOL-BREF, the higher the age, the lower the score. The same occurs when we correlate the number of children and the physical domain score, the greater the number of children, the lower the score.

Older non-vulnerable persons have higher scores in all WHOQOL-OLD and WHOQOL-BREF domains, when compared to those assessed as vulnerable.

Older non-vulnerable persons have a higher WHOQOL-OLD score than those vulnerable as. Those who reported close family contact had a higher WHOQOL-OLD score than others.

Older persons with close family contact have a higher WHOQOL-BREF score than others. Those assessed as non-vulnerable have a higher WHOQOL-BREF score than the vulnerable.

\section{DISCUSSION}

Older persons'socio-contextual characteristics in the community reinforce the data found in national and international surveys ${ }^{(17-18)}$ regarding the population profile, in which age varies between 65 and 101 years old, predominantly female, married, with little education (incomplete elementary school), retired, with a family income considered sufficient, living with up to two people and receiving some family support.

Data on quality of life show that older male persons have higher total WHOQOL-OLD $(p=0.0001)$ and WHOQOL-BREF $(p=0.0002)$ scores, with higher scores related to the death and dying domain
The data reinforce that the feminization of old age is a reality experienced worldwide and that most of these women have enough social support to maintain their health and quality of life. 
Studies in three states in Brazil identify the physical vulnerability profile of older persons in different socio-contextual situations, describing a significant number of this population with physical vulnerability characteristics and difficulty in performing activities of daily living. When comparing vulnerability with socio-contextual data, it appears that females have a higher percentage of physical vulnerability. Less family support and care and widowhood are factors that increase the physical vulnerability index, but people who still work are less vulnerable ${ }^{(19-22)}$ Brasil. Método: estudo descritivo, correlacional e de abordagem quantitativa. Foi realizada entrevista individual com a aplicação de um instrumento de caracterização sociodemográfica, a Escala de Fragilidade de Edmonton, Whoqol-bref e o Whoqol-old, no período entre 2012 e 2016. Os dados foram submetidos à análise descritiva e de correlação com testes de Kruskal-Wallis e Levin e Fox. Resultados: participaram do estudo 217 idosos, com média de idade de 68,5 $( \pm 7,35$.

The greater physical vulnerability of older females related to factors such as low education and remuneration, loneliness, social isolation and family distancing is described in the literature ${ }^{(21,23)}$. Support from family care, proximity of people with the maintenance of social networks and access to information can provide a better maintenance of functional capacities, as well as providing a greater guarantee of support in the face of physical, psychological and social needs ${ }^{(24-25)}$.

An analysis of quality of life showed that older persons had regular assessment with percentage of the WHOQOL-OLD (54.8\%) and the WHOQOL-BREF (57.4\%), with the lowest assessments occurring for physical, social, environment, autonomy, past, present and future and social participation. The results of this study are similar when compared to studies that analyzed older persons in different socio-contextual and health situations, which leads us to rethink health and policy actions related to health promotion of older persons related to active aging ${ }^{(19,26-28)}$.

Male older persons had higher total quality of life scores, with special attention to death and dying and physical domains. As for marital status, married people had better total quality of life scores, with higher scores related to the intimacy and physical domains, and those who still work better scores in the sensory and autonomy domains, those with higher education had higher scores in all quality of life domains. The data corroborate the results of studies that analyzed the relationship between quality of life and social contextual factors, international ${ }^{(28)}$ and in Brazil ${ }^{(29-30)}$.

The results of data referring to sex, marital status, education and work reinforce the concept of health presented by the WHO, in which the maintenance of autonomy and independence guarantees older persons a greater perception of being healthy and having quality of life. Thus, the health assessment of older persons should address the assessment of basic functional capacity, aiming to identify loss of functionality and consequent dependence.

Participants with sufficient family income and who had a home of their own had significantly higher scores in all WHOQOL-OLD and WHOQOL-BREF domains, with higher scores in the present-past and future, social, psychological and environmental participation domains. Social vulnerability factors, such as low family income and poor housing quality, have shown a significant negative impact on the perception of older persons' quality of life, with special attention to the physical, psychological and environmental domains, which have greater associations with the perception of health ${ }^{(31)}$. Thus, attention to the social support of older persons is a factor that can provide interprofessional health teams with more adequate support for the development of care plans for social and family support for this population ${ }^{(32)}$.

Close family care was a factor that showed a strong influence on the results of a positive assessment of quality of life. The total scores of the WHOQOL-OLD and the WHOQOL-BREF were significantly higher in older persons who reported close family contact, with the exception of the death and dying domain. Data can show that the proximity of social relationships is an important factor in improving quality of life. The family, as the main responsible for the care of its members, must provide the older person with the maintenance of close relationships to improve their quality of life assessment. Larger social networks, with more spontaneous relationships, greater geographic proximity, frequent contact and emotional proximity, are factors that improve the assessment of older persons' quality of life ${ }^{(9,33)}$ Scopus, Scholar Google, Science Direct and Online Knowledge Library (b-on.

Data analysis identified that there is a significant negative correlation between age and total score of the WHOQOL-OLD and the WHOQOL-BREF, and the higher the age, the lower the quality of life score in all evaluated domains, which corroborates the data presented by the WHO, which show that longevity is accompanied by limitations and non-communicable chronic diseases that tend to directly affect the assessment of older persons' quality of life ${ }^{(1)}$. The same negative relationship is identified when we correlate the number of children and the physical domain score, the greater the number of children, the lower the score, which may indicate the possibility of protection as an extreme family character, minimizing older persons' participation, independence, and responsiveness ${ }^{(23)}$.

More and more frequently, we can observe the overload generated by the demand for care caused by the return of children to the homes of older persons with their spouses and grandchildren. Social issues, such as unemployment, low wages and high cost of living, have led to the return of children and their families to their parents' homes, leading to the need for financial support and care for the maintenance of the home and grandchildren by the older person. Thus, for the family to be a source of effective support to encourage quality of life, there needs to be a balance between care, encouragement and autonomy for older persons $\mathrm{s}^{(23,34)}$.

In this study, people classified as non-vulnerable, when compared to those assessed as vulnerable, have a higher score in all domains of the WHOQOL-OLD and the WHOQOL-BREF, which is confirmed by the description of other data in this study when compared to studies related to thematic. Data related to assessment of older persons' physical vulnerability can corroborate the development of more effective care plans to improve the quality of life of this population ${ }^{(19,35)}$.

\section{Study limitations}

This study is limited by the fact that it only addressed older persons who assisted the service for the interview, disregarding those unable, such as bedridden people, which may characterize 
a possible bias of non-respondents, as the situation could negatively change the average of results. Therefore, we suggest further studies with this specific population.

\section{Contributions to nursing, health, and public policies}

The study can contribute to directing the interprofessional assessment of older persons, aiming at greater efficiency in the development of care plans aimed at a better assessment of physical vulnerability and consequent improvement in older persons' quality of life. Knowing the relationship between vulnerability, quality of life and the importance of its assessment enables the development of more effective behaviors, treatments and policies for professionals working with the elderly population.

\section{CONCLUSION}

In this study, factors such as female gender, low education, widowhood and not performing work-related activities are related to people assessed as vulnerable. The best quality of life scores were related to younger older persons, male, married, with higher education, with sufficient income and own house, who still perform work-related activities and have close family contact.

Family contact proved to be a protective factor for maintenance of quality of life and non-physical vulnerability of older persons, but the number of children can be a factor that negatively affects older persons' quality of life. Assessment of quality of life and analysis of family dynamics of older persons who live with more than five family members can identify factors that directly interfere with quality of life and help interprofessional health teams to create strategies to promote and protect the quality of life of this population.

There is a direct relationship between physical non-vulnerability and better quality of life scores in all domains assessed by the WHOQOL-OLD and the WHOQOL-BREF. Thus, strategies for assessing and maintaining quality of life by interprofessional health teams can provide a lower risk of physical vulnerability for older persons.

\section{REFERENCES}

1. Word Health Organization (WHO). Health situation and trend assessment - Elderly population [Internet]. 2019 [cited 2015 May 13]; Available from: http://www.searo.who.int/entity/health_situation_trends/data/chi/elderly-population/en/

2. United Nations (UM). World Population Ageing [Internet]. 2015 [cited 2015 May 13];1(1):164. Available from: http://www.un.org/en/ development/desa/population/publications/pdf/ageing/WPA2015_Report.pdf\%5Cnwww.un.org/.../population/.../WPA2009/WPA2009

3. Word Health Organization (WHO). Ten threats to global health in 2019 [Internet]. 2019 [cited 2015 May 14]. Available from: https://www. who.int/emergencies/ten-threats-to-global-health-in-2019

4. Lionis C, Midlöv P. Prevention in the elderly: A necessary priority for general practitioners. Eur J Gen Pract. 2017;23(1):202-7. https://doi.org/ $10.1080 / 13814788.2017 .1350646$

5. García Lizana F. European innovation partnership on active and healthy aging: moving from policy to action. Gac Sanit. 2013;27(5):459-62. https://doi.org/10.1016/j.gaceta.2012.09.005

6. Pivetta NRS, Marincolo JCS, Neri AL, Aprahamian I, Yassuda MS, Borim FSA. Multimorbidity, frailty and functional disability in octogenarians: a structural equation analysis of relationship. Arch Gerontol Geriatr. 2020;86:103931. https://doi.org/10.1016/j.archger.2019.103931

7. Hoogendijk EO, Romero L, Sánchez-Jurado PM, Flores Ruano T, Viña J, Rodríguez-Mañas L, et al. A new functional classification based on frailty and disability stratifies the risk for mortality among older adults: the FRADEA Study. J Am Med Dir Assoc. 2019;20(9):1105-10. https:// doi.org/10.1016/j.jamda.2019.01.129

8. Moraes E. Atenção à saúde do idoso: aspectos conceituais. Organ Panam Saúde [Internet]. 2012 [cited 2014 Sep 24];1:98. Available from: https://apsredes.org/pdf/Saude-do-Idoso-WEB1.pdf

9. Van Leeuwen KM, Van Loon MS, Van Nes FA, Bosmans JE, Vet HCW, Ket JCF, et al. What does quality of life mean to older adults? a thematic synthesis. PLoS One. 2019;14(3):e0213263. https://doi.org/10.1371/journal.pone.0213263

10. Yang $Y$, Lin M, Wang C, Lu F, Wu J, Cheng H, et al. Geriatric syndromes and quality of life in older adults with diabetes. Geriatr Gerontol Int. 2019;19(6):518-24. https://doi.org/10.1111/ggi.13654

11. Uchmanowicz I, Lisiak $M$, Wleklik $M$, Gurowiec $P$, Kałużna-Oleksy $M$. The relationship between frailty syndrome and quality of life in older patients following acute coronary syndrome. Clin Interv Aging . 2019;14:805-16. https://doi.org/10.2147/CIA.S204121

12. Paiva ATG, Bessa MEP, Moraes GLA, Silva MJ, Oliveira RDP, Soares AMG. Evaluation of functionality in families with elderly members. Cogitare Enferm. 2011;16(1):22-8. https://doi.org/10.5380/ce.v16i1.21107

13. Wright LM. Older adults and their families: an interactional intervention that brings forth love and softens suffering. J Fam Nurs. 2019;25(4):610-626. https://doi.org/10.1177/1074840719864093

14. Fleck Marcelo P, Chachamovich Eduardo, Trentini Clarissa. Development and validation of the Portuguese version of the WHOQOL-OLD module. Rev Saúde Pública. 2006;40(5):785-91. https://doi.org/10.1590/S0034-89102006000600007

15. Maia FOM, Duarte YAO, Secoli SR, Santos JLF, Lebrão ML. Cross-Cultural Adaptation of the Vulnerable Elders Survey-13(VES-13): helping in the identification of vulnerable older people. Rev Esc Enferm USP. 2012;46(spe):116-22. https://doi.org/10.1590/S0080-62342012000700017 
16. Luz LL, Santiago LM, Silva JFS, Mattos IE. First stage of the cross-cultural adaptation of the instrument The Vulnerable Elders Survey (VES-13) to Portuguese. Cad Saude Publica. 2013;29(3):621-8. https://doi.org/10.1590/S0102-311X2013000300019

17. Tavares DS, Gomes NC, Rodrigues LR, Tavares DMS, Tavares DS, Gomes NC, et al. Profile of elderly persons with metabolic syndrome and factors associated with possible drug interactions. Rev Bras Geriatr Gerontol. 2018;21(2):164-75. https://doi. org/10.1590/1981-22562018021.170154

18. Henchoz Y, Abolhassani N, Büla C, Guessous I, Goy R, Santos-Eggimann B. Change in quality of life among community-dwelling older adults: population-based longitudinal study. Qual Life Res. 2019;28(5):1305-14. https://doi.org/10.1007/s11136-019-02108-w

19. Jesus ITM, Diniz MAA, Lanzotti RB, Orlandi FS, Pavarin SCI, Zazzetta MS. Frailty and quality of elderly living in a context of social vulnerability. Texto Contexto Enferm. 2018;27(4). https://doi.org/10.1590/0104-07072018004300016

20. Amancio TG, Oliveira MLC, Amancio VS. Factors influencing the condition of vulnerability among the elderly. Rev Bras Geriatr Gerontol. 2019;22(2). https://doi.org/10.1590/1981-22562019022.180159

21. Cruz RR, Beltrame V, Dallacosta FM. Aging and vulnerability: an analysis of 1,062 elderly persons. Rev Bras Geriatr Gerontol. 2019;22(3). https://doi.org/10.1590/1981-22562019022.180212

22. Cabral JF, Silva AMC, Mattos IE, Neves ÁQ, Luz LL, Ferreira DB, et al. Vulnerability and associated factors among older people using the Family Health Strategy. Cienc Saude Coletiva. 2019;24(9):3227-36. https://doi.org/10.1590/1413-81232018249.22962017

23. Inouye K, Barham EJ, Pedrazzani ES, Pavarini SCI. Relations between social vulnerability and perceptions of family Support and quality of life among elderly people. Psicol Reflex Crít. 2010;23(3):582-92. https://doi.org/10.1590/S0102-79722010000300019

24. Montayre J, Thaggard S, Carney M. Views on the use of the term 'elder orphans': a qualitative study. Health Soc Care Community. 2019;28(2):341-6. https://doi.org/10.1111/hsc.12865

25. Gonçalves LTH, Leite MT, Hildebrandt LM, Bisogno SC, Biasuz S, Falcade BL. Living together and family care at the fourth age: quality of life for seniors and their caregivers. Rev Bras Geriatr Gerontol. 2013;16(2):315-25. https://doi.org/10.1590/S1809-98232013000200011

26. Hunt C, Zahid S, Ennis N, Michalak A, Masanic C, Vaidyanath C, et al. Quality of life measures in older adults after traumatic brain injury: a systematic review. Qual Life Res. 2019;28:3137-51. https://doi.org/10.1007/s11136-019-02297-4

27. Okuno MFP, Rosa AS, Lopes MCBT, Campanharo CRV, Batista REA, Belasco AGS. Quality of life of hospitalized octogenarians. Rev Bras Enferm. 2019;72(2):43-8. https://doi.org/10.1590/0034-7167-2017-0781

28. Ko H, Park YH, Cho B, Lim KC, Chang SJ, Yi YM, et al. Gender differences in health status, quality of life, and community service needs of older adults living alone. Arch Gerontol Geriatr. 2019;83:239-45. https://doi.org/10.1016/j.archger.2019.05.009

29. Lima ALB, Espelt A, Lima KC, Bosque-Prous M, Lima ALB, Espelt A, et al. Activity limitation in elderly people in the European context of gender inequality: a multilevel approach. Cienc Saude Coletiva. 2018;23(9):2991-3000. https://doi. org/10.1590/1413-81232018239.20662016

30. Almeida-Brasil CC, Silveira MR, Silva KR, Lima MG, Faria CDCM, Cardoso CL, et al. Quality of life and associated characteristics: application of WHOQOL-BREF in the context of Primary Health Care. Cienc Saude Coletiva. 2017;22(5):1705-16. https://doi. org/10.1590/1413-81232017225.20362015

31. Ferreira LK, Meireles JFF, Ferreira MEC. Evaluation of lifestyle and quality of life in the elderly: a literature review. Rev Bras Geriatr Gerontol. 2018;21(5):616-27. https://doi.org/10.1590/1981-22562018021.180028

32. Vagetti GC, Moreira NB, Barbosa Filho VC, Oliveira V, Cancian CF, Mazzardo O, et al. Aspects of quality of life associated with self-rated health: a study of elderly women from a physical activity program in low-income neighborhoods in Curitiba in the state of Paraná, Brazil. Cienc Saude Coletiva. 2013;18(12):3483-93. https://doi.org/10.1590/S1413-81232013001200005

33. Gouveia OMR, Matos AD, Schouten MJ. Social networks and quality of life of elderly persons: a review and critical analysis of literature. Rev Bras Geriatr Gerontol. 2016;19(6):1030-40. https://doi.org/10.1590/1981-22562016019.160017

34. Fernandes MGM, Garcia LG. The meaning of old age for elderly men and women. Saúde Soc. 2010;19(4):771-83. https://doi.org/10.1590/ S0104-12902010000400005

35. Martín-Fernández J, Ariza-Cardiel G, Polentinos-Castro E, Sanz-Cuesta T, Sarria-Santamera A, del Cura-González I. Explaining differences in perceived health-related quality of life: a study within the Spanish population. Gac Sanit. 2018;32(5):447-53. https://doi.org/10.1016/j. gaceta.2017.05.016 